\title{
Caracterización molecular y fisiológicas de levaduras de suelo trumao
}

(Molecular and physiological characterization of yeasts of trumao soil)

\author{
Paola Díaz Navarrete ${ }^{1}$, Camila Aranda González ${ }^{1}$, Roberto Godoy Borqez $^{2}$, \\ Oscar Martínez Viveros ${ }^{1}$,Aldo González Becerra ${ }^{3}$, Eduardo Valenzuela Flores ${ }^{1 *}$ \\ 1. Instituto de Bioquímica y Microbiología,Facultad de Ciencias, \\ Universidad Austral de Chile, \\ 2. Instituto de Ciencias Ambientales y Evolutivas, Facultad de Ciencias, \\ Universidad Austral de Chile, \\ 3. Centro de Biología Molecular Severo Ochoa. \\ Consejo Superior de Investigaciones Científicas,Madrid, España. \\ *Autor para correspondencia: evalenzu@uach.cl \\ RECIBIDO:28 de Octubre de 2016 \\ APROBADO:24 de Noviembre de 2016
}

DOI:10.22370/bolmicol.2016.31.2.485

LOS AUTORES DECLARAN NO TENER CONFLICTO DE INTERESES

Palabras clave: levaduras, PCR-RFLP, ITS-5.8S, suelo trumao

Key words: yeasts, PCR-RFLP, ITS-5.8S, trumao soil

RESUMEN

Las levaduras juegan un importante rol en la naturaleza siendo el mayor reservorio de ellas el suelo. Mediante el método de las diluciones seriadas y posterior siembra en agar Sabouraud se aislaron en cultivo puro 77 cepas de levaduras desde un mismo suelo trumao del sur de Chile, usado como pradera permanente (30 cepas), pradera en rotación (30 cepas) y como control bosque nativo (17 cepas), estas cepas se identificaron molecularmente por PCR-RFLP en conjunto con secuenciación del rDNA de ITS-5.8S, además se realizo una caracterización fisiológica (asimilación fuente de carbono, de nitrógeno y fermentación de azucares) a cada cepa. Mediante las técnicas moleculares las 77 ce- pas se reunieron en 10 grupos, de estos solamente tres grupos se pudieron identificar a nivel de especie y uno hasta género: Devariomyces hansenii. Pichia fermentan. Kazachstania exigua., Candida sp.

\section{ABSTRACT}

Yeasts plays an important role in nature, It is the largest reservoir of soil them. By the method of serial dilutions and subsequent planting in Sabouraud agar were isolated in pure culture 77 strains of yeast from the same volcanic ash soil of southern Chile, used as permanent pasture (30 strains), rotation pasture (30 strains) and native forest as a control (17 strains), these strains were identified molecularly by PCR-RFLP in conjunction with 
Caracterización molecular y fisiológicas de levaduras de suelo trumao - Díaz P. et al

rDNA sequencing ITS-5.8S, physiological characterization addition was performed to each strain (carbon and nitrogen source assimilation and fermentation of sugars). Using molecular techniques met the 77 strains in 10 groups; only three groups could be identified to species level and one to gender: Devariomyces hansenii; Pichia fermented; Kazachstania exigua; Candida sp.

\section{INTRODUCCIÓN}

Botha (2011), señala que los hongos al ser un componente importante de todos los ambientes terrestres, tienen un impacto considerable sobre los procesos fundamentales del suelo (descomposición, la agregación, liberación y almacenamiento de nutrientes). Las levaduras son un tipo de hongos pertenecientes al Reino Fungi, son abundantes en la naturaleza y se encuentran en una serie de reservorios (agua, suelo, hojas, flores, frutos, piel, insectos, etc.) en los que pueden vivir. El suelo es el último reservorio para almacenar y también para el desarrollo de ciertas especies de levaduras (Wuczkowski y Prillinger., 2004), encontrándose una amplia diversidad filogenéticamente no relacionadas, que forman parte de la comunidad microbiana del suelo. La diversidad de levaduras en el suelo ha sido examinada en diferentes partes del mundo, desde suelos tropicales hasta antárticos (Slavikova y Vadkertiova., 2000). La presencia de estos hongos en el suelo está dado por diversas características como: tipo de suelo, clima y perturbación antrópica. Con respecto a este último, existen estudios que demuestran como la actividad humana influye sobre la diversidad y las estructuras comunitarias de las levaduras en el suelo, así, Slavikova y Vadkertiova (2003), evaluaron levaduras en suelo con distintos tipos de cultivo (maíz, remolacha y papas) comparadas con suelos no labrados, determinaron que en suelos labrados existe una disminución de la población de levaduras y asocian este fenómeno al uso de pesticidas y fungicidas. Yurkov et al., (2012), analizaron la diversidad de levaduras en suelos que sufrieron un cambio de bosque a pastizales, el análisis de abundancia de especie y estructura de las comunidades determinó que suelos con pastizales albergan predominantemente levaduras Ascomycetes a diferencia de los suelos de bosque donde la estructura de las comunidades es más heterogénea.

Por su parte la identificación molecular de las levaduras es necesaria por el potencial económico que pueden presentar en distinta áreas como: agricultura, médica o medioambiental. La caracterización de levaduras está basada en muchas técnicas moleculares, que incluyen las secuencias del gen rDNA y/o regiones como los espacios transcritos internos ITS. Estas técnicas son rápidas, fiables y precisas y por lo tanto adecuadas para el cribado rápido de cepas aisladas. Se ha demostrado que la región interna entre los espacios transcritos ITS (no codificante y variable) y el gen 5.8 rRNA (codificante y conservado) pueden ser útiles en la medición de relaciones filogenéticas, pues estas regiones presentan mayores diferencias intraespecífica (Fernández-González et al., 2001). Actualmente las levaduras son utilizadas en diferentes líneas de investigación entre ellas la producción de biofertilizantes y producción de lípidos. Los biofertilizantes son formulaciones de microorganismos beneficiosas, que después de la aplicación pueden aumentar la disponibilidad de nutrientes por su actividad biológica así ayudan a mejorar la salud del suelo (Kupper, 2006), además resulta urgente mejorar las prácticas agrícolas para garantizar la producción de alimentos de manera sustentable con el medio ambiente. Por otra parte, la generación de lípidos a partir de levaduras ha sido reportado por varios autores (Chang et al., 2013; Kitcha y Cheirsilp, 2011) siendo las especies más prometedoras para la producción de grasas las siguientes: Ansenula saturnus, Candida curvata, C. tropicales, Cryptococcus albidus, C. curvatus, C. laurentii, C. terricolus, Lipomyces starkeyi, L. tetrasporus, Rhodosporidium toruloides, Rhodotorula glutinis, $R$. gracilis, R. mucilaginosa, Trigonopsis variables, Trychosporon cutancum, $T$. pullulans, Yarrowia lipolítica y Y. paralipolitica 
entre otras (Papanikolaou y Anggelis., 2002; Li et al., 2007).

El objetivo del presente estudio fue identificar molecularmente y caracterizar metabólicamente las levaduras presentes en un mismo suelo trumao (de la Región de los Ríos, Chile), sometido a dos manejos agrícolas distintos.

\section{MATERIALES Y MÉTODOS}

\subsection{Recolección de Muestra de suelo}

En cada lugar, desde un suelo Hapludant (trumao), ubicado en la localidad de Marquina, Valdivia- Chile. (673.75 E, 5625.5 N UTM., Cuadrante H18), se recolectaron 400 gr de suelo de los primeros $10 \mathrm{~cm}$, los lugares de recolección fueron una pradera permanente (PP), una pradera en rotación (PR) y como control un bosque nativo $(\mathrm{BN})$. Las muestras de suelo se depositaron independientemente en bolsas plásticas estériles y se trasladaron al laboratorio de Micología del Instituto de Bioquímica y Microbiología de la Universidad Austral de Chile.

\subsection{Aislamiento de levaduras}

El aislamiento de las levaduras fue realizado por el método de dilución seriada, se pesaron 10 gr de la muestra de suelo respectiva y se depositaron en un matraz, se agregaron $90 \mathrm{~mL}$ de agua destilada estéril, la mezcla obtenida se agitó manualmente hasta total disolución del suelo, luego se extrajo con una pipeta estéril $1 \mathrm{~mL}$ de la mezcla y se depositó en un tubo que contenía $9 \mathrm{~mL}$ de agua destilada estéril (obteniéndose una dilución 10-2), a partir del tubo que contenía la dilución 10-2 se extrajo con una nueva pipeta estéril $1 \mathrm{~mL}$ de la dilución y se deposito en un tubo que contenía $9 \mathrm{~mL}$ de agua destilada estéril (obteniéndose una dilución 10-3), así se realizaron diluciones hasta 10-6, teniendo la precaución de usar para cada dilución una pipeta estéril. $1 \mathrm{~mL}$ de la dilución respectiva se depositó en una placa Petri vacía a la cual se le añadió $0,5 \mathrm{~mL}$ de una mezcla de antibióticos (penicilina y estreptomicina 1:1) y $15 \mathrm{~mL}$ de agar
Sabouraud, una vez solidificado el agar las placas se incubaron a $23 \pm 2{ }^{\circ} \mathrm{C}$ por 7 días. Terminada la incubación se seleccionaron 30 colonias de levaduras para cada tipo de manejo y 17 colonias para el suelo control (usando criterios morfológicos de color y tamaño de la colonia), las que constituyeron las 77 cepas de levaduras del presente estudio.

\subsection{Extracción del DNA y amplificación de la re- gión ITS rDNA}

Las levaduras se cultivaron en Yeast Peptone Dextrose (YPD) durante $30 \mathrm{~h}$ a $25^{\circ} \mathrm{C}$, el DNA de las cepas fue extraído con el kit Yeast DNA EZNA usando las indicaciones del proveedor. La región 5,8S-ITS del ADN ribosomal nuclear (ADNr) se amplificó con los partidores ITS1 (5' TCCGTAGGTGAACCTGCG G-3') e ITS4 (5' TCCTTCCGCTTATTGATATGC G-3') e ITS1 (5' TCC GTA GGT GAA CCT GCG G 3') y NL4 (5' GGT CCG TGT TTC AAG ACG G 3'). La reacción PCR se llevó a cabo en $25 \mu \mathrm{l}$ compuesta por GoTaq ${ }^{\circledR}$ Green Master Mix (Taq DNA polymerase, dNTPs, $\mathrm{MgCl} 2$ ) (Promega) y 0,5 $\mu \mathrm{l}$ de los primer Forward y Reverse. Las condiciones de amplificación para los primer ITS1-ITS4 fueron, denaturación inicial $\left(2 \min\right.$ a $\left.95^{\circ} \mathrm{C}\right)$, denaturación final (1 min a $\left.95^{\circ} \mathrm{C}\right)$, annelling $\left(2 \mathrm{~min}\right.$ a $\left.56^{\circ} \mathrm{C}\right)$, extensión $\left(2 \mathrm{~min}\right.$ a $\left.72^{\circ} \mathrm{C}\right)$, extensión final $\left(10 \mathrm{~min}\right.$ a $\left.72^{\circ} \mathrm{C}\right)$. Para los primer ITS1-NL4 las condiciones fueron, denaturación inicial $\left(2 \min\right.$ a $\left.95^{\circ} \mathrm{C}\right)$, denaturación final $\left(94^{\circ} \mathrm{C}\right.$ por $\left.1 \mathrm{~min}\right)$, annelling $\left(40 \mathrm{~s}\right.$ a $52^{\circ} \mathrm{C}$ ), extensión $\left(1 \mathrm{~min}\right.$ a $\left.72{ }^{\circ} \mathrm{C}\right)$ extensión final $(10 \mathrm{~min}$ a $72{ }^{\circ} \mathrm{C}$ ) ambas en 30 ciclos. $4 \mu 1$ del producto PCR se analizaron al 1,5\% de agarosa en TAE 1X, y visualizados en el transluminador Foto/UV21. Se utilizó el marcador de peso molecular de 100-pb DNA (Thermo Scientific). La concentración del DNA fue medida en un Nanodrop, Infinite M200. El DNA amplificado fue purificado y enviado para secuenciación a MACROGEN, KOREA.

\subsubsection{Técnica PCR-RFLP}

Para la técnica PCR-RFLP los productos PCR de la región 5.8S-ITS fueron digeridos sin 
Caracterización molecular y fisiológicas de levaduras de suelo trumao - Díaz P. et al

purificación adicional $(5 \mu 1)$ con las enzimas de restricción CfoI, HaeIII (Promega), Hinfl (New England Biolabs) según condiciones del proveedor. La incubación fue a $37^{\circ} \mathrm{C}$ por $2,5 \mathrm{~h}$. Los fragmentos fueron separados al 3,5\% en gel de agarosa en TAE $1 \mathrm{X}$ por $2 \mathrm{~h}$ a $80 \mathrm{~V}$. El Tamaño de bandas fue estimado con el marcador de 100-pb DNA, (Thermo Scientific). Para la identificación de las secuencias obtenidas se usó la base de datos Genbank con la herramienta (BLAST), http://www.ncbi.nlm. nih.gov/BLAST. Para el RFLP in silico los patrones de restricción fueron predichos por el programa http://www.restrictionmapper.org/ (programa de libre acceso). El árbol filogenético se realizó con MEGA5.1 con el algoritmo Neighbor-Joining, y el modelo Kimura 2-Parametros (K-2-P), para la estimación de las distancias el booststrap fue de 1000 réplicas.

\subsection{Determinación metabólica de las cepas de levaduras}

Cada cepa fue caracterizada mediante la metodología tradicional propuestas por Kreger-van Rij (1994), estas son: (i) determinación mediante auxograma del uso de distintas fuentes de carbono (Acido succínico, Ácido cítrico, Almidon, Celobiosa, D-arabinosa, D-glucitol, D-manitol, D-xilosa, D-ribosa, DL-ácido láctico, Galactitol, Galactosa, Glicerol, Inositol, Lactosa, L-aravinosa, L-Rhamnosa, L-sorbosa, Maltosa, Melibiosa, Melizotosa, Rafinosa, Ribitol, Sacarosa, Trehalosa), se mezclaron $0,5 \mathrm{~mL}$ de la suspensión de levaduras (turbidez 0,1 de McFarland = 102 UFC de levaduras $/ \mathrm{mL}$ ) con $10 \mathrm{~mL}$ de agar Yeast Nitrogen Base (YNB), la mezcla obtenida se deposito en una placa Petri estéril y vacía. Una vez solidificada la mezcla se procedió a depositar en cuatro puntos equidistantes de la placa y cerca del borde las fuentes de carbono seleccionadas, siendo obligatoria la Glucosa (control), luego las placas se incubaron a $23{ }^{\circ} \mathrm{C}$ y se examinaron cada 2 días durante una semana, el crecimiento cualitativamente de la cepa de levadura fue dado como positivo $(+)$, positivo débil $(+/-)$ y negativo (-). (ii) Asimilación de fuentes de nitró- geno (nitrato, nitrito y urea) también fue realizada por auxograma, cambiando solamente el medio base, se uso el agar Yeast Carbon Base (YCB) y (iii) Determinación de fermentación: glucosa (control positivo), Almidón, D-galactosa, D-xilosa, Fructosa, Lactosa, Maltosa, Sucrosa, Trehalosa. Como medio de cultivo se uso caldo extracto de levadura al 0,1\%, al que se le agregó el azúcar a evaluar al 2\%. Así cada tubo está constituido por una campana Durhan, $3 \mathrm{~mL}$ de medio de cultivo y 1,5 mL del azúcar a ensayar. A cada tubo se le agrego $0,1 \mathrm{~mL}$ de la suspensión de la levadura respectiva (a $0,1 \mathrm{McF}$ arland), luego los tubos fueron incubados a $23{ }^{\circ} \mathrm{C}$ durante un mes, cada día se determinó a ojo desnudo si eran positivos (turbidez y gas en la campana Durham).

\section{RESULTADOS Y DISCUSIÓN}

\section{Identificación molecular mediante PCR-RFLP y Secuenciación}

La amplificación de la región ITS-5.8S del rDNA de cada una de las cepas de levaduras (77 cepas en total) mostraron diferencias en cuanto al tamaño de la región amplificada (entre 421 y 678 $\mathrm{pb}$ ), dando cuenta de la variabilidad que presenta esta región del rDNA entre especies diferentes.

Se ha descrito, que los ITS ("internal transcriber spacer") del rDNA son un buen marcador para el estudio del polimorfismo que se relaciona con la variaciones genéticas entre e intraespecies (Lozano et al., 2002). Como una caracterización de las cepas aisladas de los tres lugares (PP, PR y BN) de un mismo suelo Hapludant (trumao), se realizó un análisis amplificando mediante PCR, la región ITS1-5.8SI-TS2 y parcialmente el gen 26S. Para ello se utilizó los partidores ITS1 e ITS4 y/o NL4 que amplifican un fragmento de DNA de aproximadamente $500 \mathrm{pb}$, dependiendo del género estudiado. Posteriormente el análisis de restricción, utilizando las endonucleasas CfoI, HaeIII y HinfI, permitió establecer 10 perfiles de restricción diferentes (10 taxa), lo cuales eran indicativos para cada especie (Tabla 1). De estas 10 taxas solamen- 
Caracterización molecular y fisiológicas de levaduras de suelo trumao - Díaz P. et al

te 4 grupos se pudieron identificar a nivel de especie, (básicamente porque aún no se han reportados los patrones de restricción para muchas especies de levaduras) estas son; Candida saitoana; Deva- riomyces hansenii; Kazachstania exigua y Pichia fermentan, por comparación con patrones de restricción disponibles en la literatura (Esteve- Zarzoza et al. 1999).

Tabla 1. Tamaño (en pares de bases) de los productos PCR y los fragmentos de los análisis de restricción del gen 5.8S-ITS.

\begin{tabular}{|lccccc|}
\hline Taxa & $\begin{array}{c}\text { Numero } \\
\text { cepas }\end{array}$ & bp & CfoI & HaeIII & HinfI \\
& 1 & 616 & $556+50$ & $385+132+99$ & $303+209+96$ \\
\hline Candida saitoana & 9 & 640 & $295+284+51$ & $421+139+80$ & $316+316$ \\
Devariomyces hansenii & 1 & 447 & $157+92+88+86+69$ & $334+78+35$ & $250+197$ \\
Pichia fermentans & 5 & 572 & $304+268$ & n.c & $275+173+124$ \\
schizoblastoporiom & & & & & \\
starkeyiihenricii & 11 & 533 & $269+264$ & $479+54$ & $229+139+87+61$ \\
Trichosporon ducitum & 3 & 533 & $267+266$ & $479+54$ & $229+149+89+61$ \\
Trichoporon lignicola & 1 & 530 & $266+264$ & $n . c$ & $287+235$ \\
Trichosporon & & & & & \\
miniiliforme & 7 & 528 & $265+263$ & $474+54$ & $234+225+89+61$ \\
Trichosporon porosum & 1 & 421 & $216+205$ & n.c & $226+207$ \\
Candida sp. & 38 & 678 & $319+201+76+73$ & $476+202$ & $340+337$ \\
Kazachstania exigua. & & & & & \\
\hline n.c: no corta sitio. & & & & & \\
\hline
\end{tabular}

Con el propósito de lograr identificar las cepas desconocidas (no identificadas por PCRRFLP) y de reconfirmar las identificadas, los productos PCR de las 77 cepas fueron secuenciados y luego comparados con secuencias de base de datos del GenBank, los seis grupos no identificados por PCR-RFLP correspondían a: C. saitoana; Trichosporon ducitum; Trichosporon lignícola; Trichosporon miniiliforme; Trichosporon porosum y Schizoblastoporiom starkeyiihenricii, todas por sobre un $99 \%$ de identidad. Con respecto a las cepas identificadas por la técnica PCR-RFLP, mediante secuenciación se logró reconfirmar su identidad, lo que indicaría, que para el caso de que existan los patrones de restricción de las levaduras, esta metodología (RFLP) provee de información certera, fiable y rápida en su ejecución.

Otro análisis desarrollado a partir de las secuencias fue el RFLP in silico en donde se pudo establecer los fragmentos obtenidos con las endonucleasas, para cada una de las cepas (Tabla 1). Para las especies C. saitoana; D. hansenii; K. exigua; P. fermentan; S. starkeyiihenricii y Candida sp., los perfiles de restricción obtenidos con las tres enzimas permitieron establecer claramente patrones únicos, no sucediendo lo mismo para las especies del género Trichosporon, en donde por ejemplo, entre T. dulcitum; T. lignícola y T. porosum los patrones de restricción obtenidos son similares, lo que daría cuenta de la necesidad de utilizar otras enzimas de restricción para la diferenciación en- 
tre ellas o la utilización de una región del DNA diferente como las regiones IGS (espacios intergénicos) localizadas entre la 26S y la $18 \mathrm{~S}$ (Romero et al, 2005). Para el caso de T. miniiliforme si bien el producto PCR y los cortes con las enzimas CfoI y HinfI son similares que las obtenidas para las otras especies de Trichosporon, existe una clara diferencia en el patrón de restricción obtenido con la enzima HaeIII, en donde no existió corte, probablemente debido a que en el sitio de clivaje de la enzima de restricción existió un cambio (mutación). Sin embargo la similitud de los patrones obtenidos permite establecer una correlación entre estas especies (estrechamente relacionadas), pero no así la identificación a través de esta técnica para las especies del género Trichosporon aisladas en el presente trabajo. La región ITS-5.8S es altamente homóloga en las especies del género Trichosporon, por lo cual puede ser considerado filogenéticamente monofiletico (Middelhoven et al 2001), siendo necesario regiones con una mayor divergencia como es el caso de las secuencias IGS según lo concluye Sugita et al., (2002) en su estudio del análisis de la secuencias IGS de 25 especies del género Trichosporon. Siguiendo esta misma línea, existe un grupo de levaduras Saccharomyces sensu stricto, en donde al igual que para Trichosporon sp., no presentan diferencias en los patrones de banda con las enzimas de restricción descritas (Esteve -Zarzoza et al. 1999). Segura, (2010) del mismo modo reporta que para la especies de levadura Kuyvemyces lactis y Kluveromyces marcianus los patrones de banda son muy similares lo que resultaría difícil la correcta identificación a través de la técnica PCR-RFLP y que no solo a nivel molecular es complicado sino también la correcta identificación morfofisiológica, al igual que sucede con el género Trichosporon (Middelhoven et al., 2001). Por lo cual y considerando estos antecedentes, para el caso de las levaduras T. dulcitum, T. lignícola y T. porosum sería necesario, probar con otras endonucleasas que generen patrones de polimorfismo diferentes para cada especie, o como ya se ha mencionado la utilización de una región que presente mayor hipevariabilidad como las regiones IGS que han sido utilizadas para identificar varias levaduras Basidiomycetes (Nguyen et al., 2009).

La levaduras $K$. exigua representa el 38\% de la totalidad de las cepas aisladas de suelo trumao (pero mayoritariamente del suelo de PP). $K$. exigua se puede encontrar en diferentes nichos, como aguas residuales, suelo, frutas entre otras (Barnett et al., 2000). Levaduras del género $\mathrm{Ka}$ zaschtania han sido reportadas de diversos tipos de suelo como lo descrito por Yurkov et al., (2012), quienes aislaron Kazachstania piceae (suelo forestal) y Kazastania servazzi (suelo de pradera) en muestras con distinto manejo del suelo. Con respecto a los patrones de restricción obtenidos para las cepas de levaduras del género Kazachstania en el presente estudio cada una de ella resultó ser similar, en la figura 1 se puede apreciar el perfil de restricción obtenido para las tres enzimas evaluadas (CfoI, HaeIII y HinfI) en cepas aisladas del suelo de PP, estos patrones son similares a los obtenidos por Phan et al., (2011) y Esteve-zarzoso et al., (1999).

Figura 1. Digestiones con las enzimas de restricción CfoI, HaeIII, HinfI para las cepas PR17 hasta PR21 (Kazachtania exigua). Carril $1=$ marcador molecular. Cepa PR17, carriles $2=(\mathrm{CfoI}) 3=(\mathrm{HaeIII}), 4=$ (HinfI). Cepa PR18, carriles $=6$ (CfoI) 7 $=($ HaeIII $), 8=($ HinfI $)$. Cepa PR19, carri-

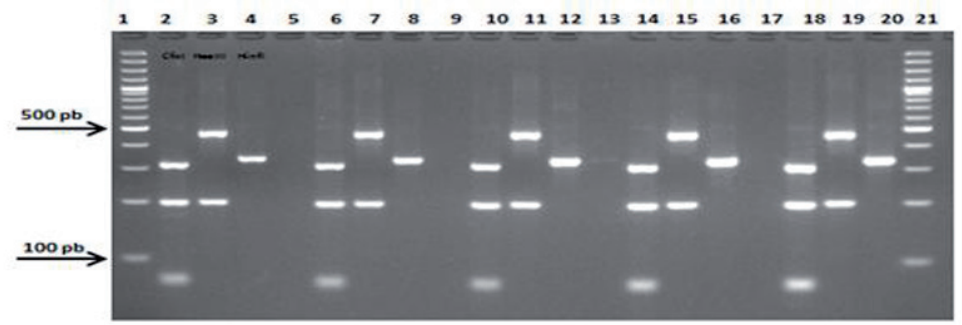
les $10=(\mathrm{CfoI}) 11=($ HaeIII $), 12=($ HinfI $)$. Cepa PR20, carriles $=14(\mathrm{CfoI}) 15=($ HaeIII $), 16=($ HinfI $)$ Cepa PR21, carriles $=18(\mathrm{CfoI}) 19=($ HaeIII $), 20=($ HinfI $)$ Carril $21=$ marcador molecular. 
Estas mismas cepas analizadas a partir de la secuenciación de la región ITS1-5,8S-ITS2 y parcialmente el gen $26 \mathrm{~S}$, se puede ver como al igual que la metodología PCR-RFPL, corresponderían a una misma cepa de levaduras.

En la Figura 2 se presenta el árbol filogenético de las cepas aisladas en el suelo manejado agrícolamente de $\mathrm{PR}$, se aprecia que las cepas ( $\mathrm{P}$ $\mathrm{R} 5,14,15,17,18,19,20,21,22,13,30)$ forman parte del clado con la cepa de referencia $K$. exigua (JQ808008.1). Del mismo modo las cepas (PR $25,26,24,23,10,8,6,4,3,1,27)$ forman parte de un clado con la cepa de referencia $T$. dulcitum (FR716597), siendo identificadas como tal. Estas dos levaduras serían las que se presentan mayoritariamente en este tipo de suelo. Además a diferencia de las cepas aisladas de PP y BN, en el suelo de PR existe una mayor variabilidad de especies. Esta situación se puede asociar a que este tipo de suelo ha debido albergar microorganismos que metabólicamente sean dinámicos y con una capacidad de aclimatación a cambios físicos y químicos del suelo debido a la rotación de cultivo. Si se compara la composición de levaduras se puede apreciar que las levaduras que alberga son aquellas derivadas del suelo control, es decir del suelo de BN y también del suelo usado como PP.

En el suelo de bosque nativo, las cepas predominantes correspondieron a D. hansenii (35\%), T. dulcitum y T. porosum (35\%) y S. starkeyi-henricii (12\%), Mestre et al. (2011), en su estudio de suelo de bosque de la Patagonia Argentina señalan que especies como $T$. dulcitum y $T$. porosum participarían activamente en los procesos de degradación y mineralización del material vegetal en descomposición. La conservación de los bosques conduce a un pronunciado dominio de algunos pedobiontes $T$. dulcitum; $T$. porosum y Cr. podzolicus altamente especializados en habilidades como la descomposición de polisacáridos complejos y algunos compuestos aromáticos (Yurkov et al.,
2012). Además Botha, (2011) ha señalado que levaduras pertenecientes a los géneros Candida; Cryptococcus; Rhodotorula; Sporobolomyces; Trichosporon; Williopsis y Yarrowia también son capaces de aumentar directamente el crecimiento de las plantas (promoción crecimiento vegetal). En el suelo de PP se aisló mayoritariamente cepas del genero Kazachstania ( 87\%). Esto se condice con Yurkov et al. (2012), establecen que a medida que se hace más intensivo el manejo del suelo existirá una mayor proporción de levaduras pertenecientes a Ascomycota, la alta presencia de esta levadura en suelos de PP se puede asociar, a diferencia de levaduras Basidomycota, a la falta de maquinaria enzimática para lograr degradar compuestos complejos, sino que son capaces de crecer rápidamente ante la presencia de compuestos más simples como mono, di o trisacáridos (Fonseca y Inácio 2006), esta situación está dada por las constantes fertilizaciones dadas a este tipo de suelo. El suelo que permitió una mayor variabilidad de cepas de levaduras fue el suelo de PR, cepas de: T. dulcitum 37\%, S. starkeyiihenricii 10\%, Kazachstania sp., 37\%, T. lignícola 6\%, Candida sp 6\%. T. miniiliforme 3\%. Esto se podría explicar, considerando, que para PR es necesario un cultivo previo para la fertilización del suelo lo que conduciría a la mayor presencia de levaduras Basidiomycota.

De forma general en la figura 3 se aprecia los porcentajes de aislación de todas las especies y genero determinados en el presente estudio, para los diferentes manejos del suelo trumao, las cepas que fueron mayoritariamente aisladas, independientemente del manejo agrícola, corresponden a $K$. exigua (49\%), T. dulcitum (14\%), D. hansenii $(12 \%)$ y T. porosum $(9 \%)$, destacando la alta presencia de la cepa $K$. exigua, sin embargo se ha de considerar que estas levaduras solamente fueron aisladas de PP (75\%) y PR (25\%) en bosque nativo la mayoría de las levaduras aisladas correspondieron a géneros Basidiomycota. 


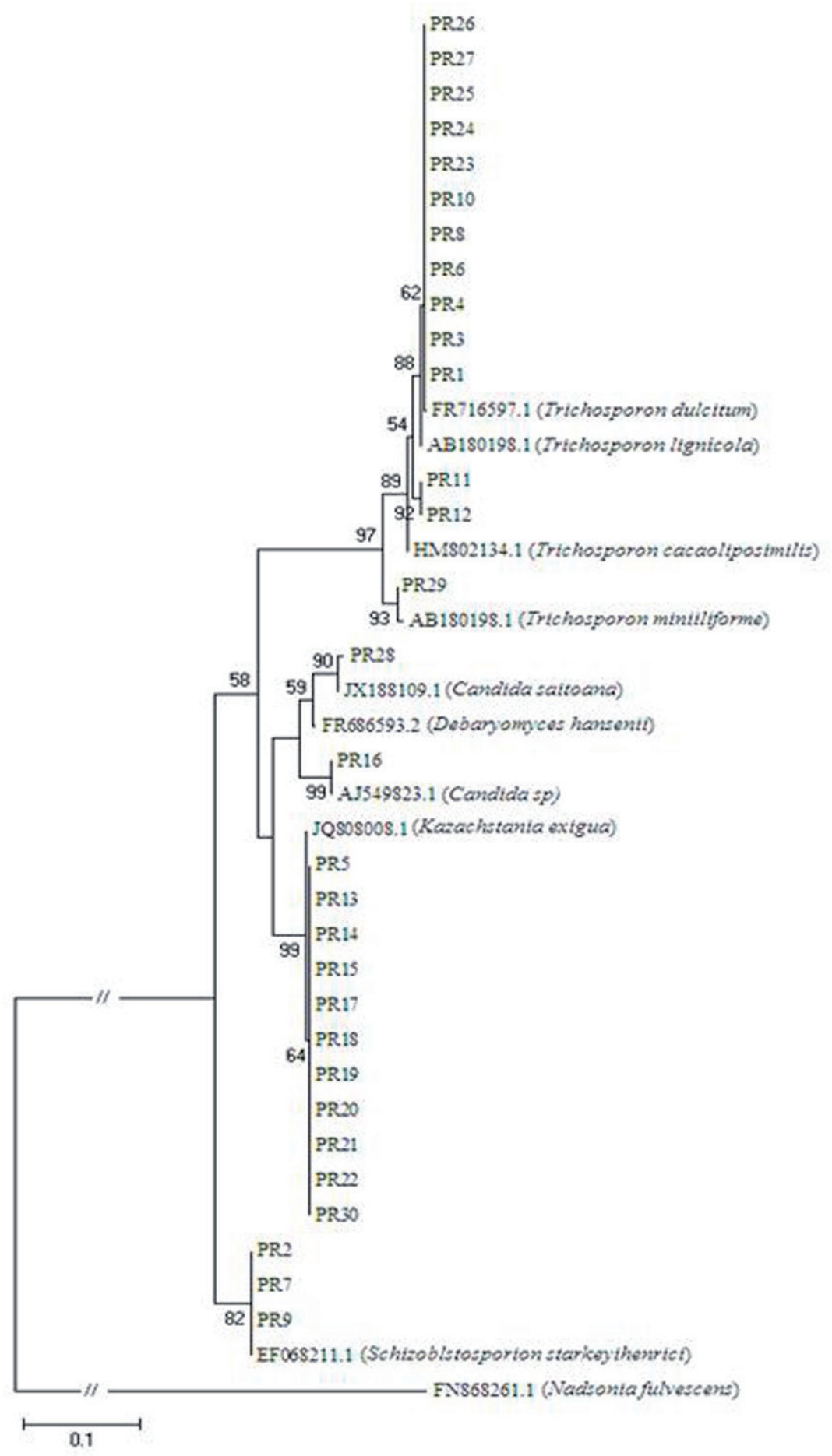

Figura 2. Árbol filogenético de las levaduras de pradera en rotación comparando la secuencia nucleotídica de la región ribosomal ITS1-5.8S-ITS2 y fragmento del 26S con los publicados en GenBank (se presentan los números de acceso y entre paréntesis el nombre científico de la levadura). Basado en el método "Neighbor-Joining", un bootstrap de 1000. La distancia evolutiva fue realizada usando el Método "K2P". El análisis filogenético se llevó a cabo en MEGA5. 


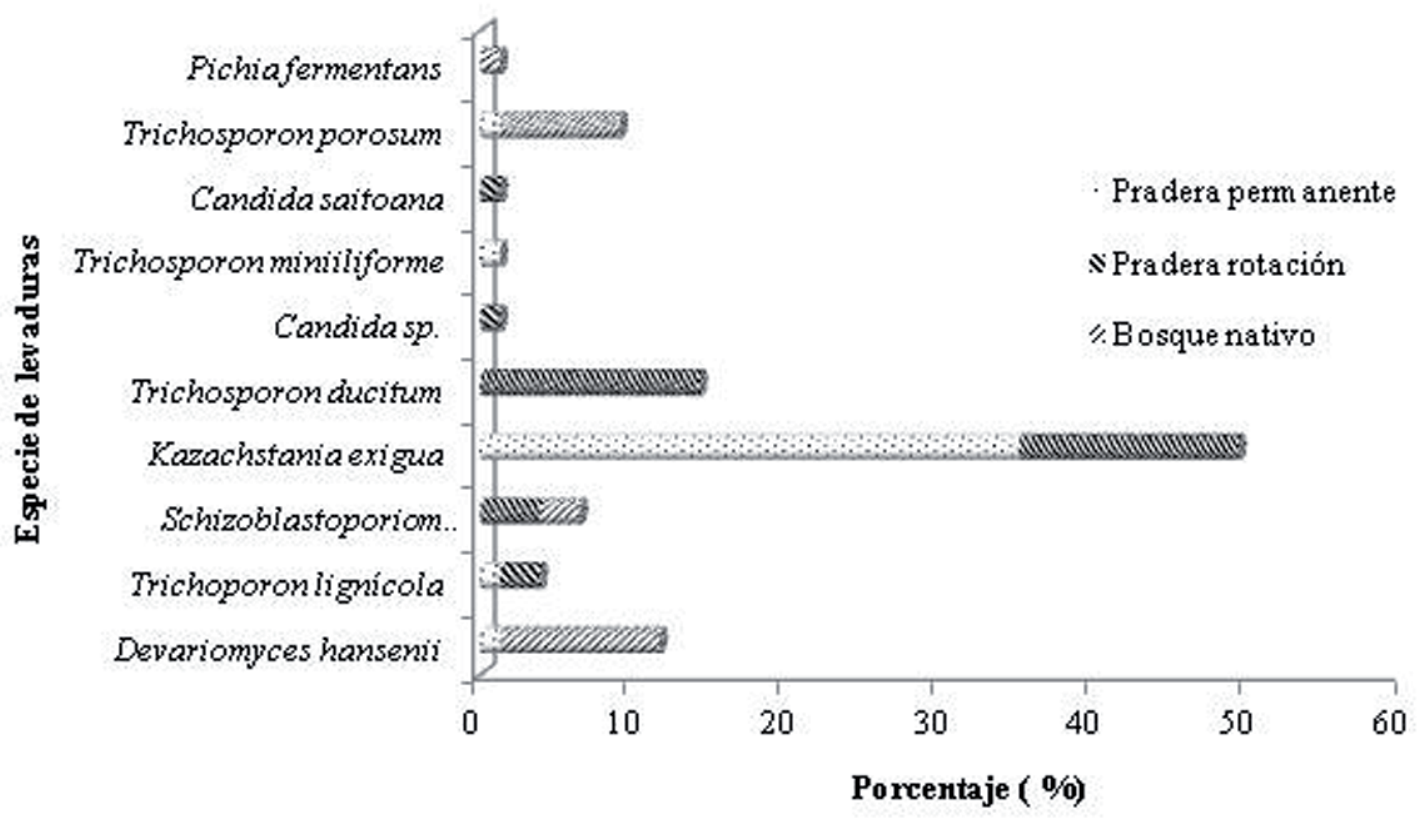

Figura 3. Porcentaje de levaduras aisladas desde suelo trumao de acuerdo a su uso agronómico.

\subsection{Caracterización de las cepas de levaduras}

Las cepas del presente estudio fueron agrupadas según los resultados de la secuenciación, según este análisis del total de cepas de levaduras (77) habrían 10 taxas, a partir de ello se agruparon las cepas y se procedió a evaluar para cada cepa sus características fisiológicas de acuerdo al grupo.

Para la asimilación de fuentes de carbono (tabla 2), la cepa de P. fermentans (B27) obtuvo un perfil de asimilación de fuentes de carbono similar al descrito por Kreger-van Rij (1994), ninguna de las cepas del presente estudio fue capaz de asimilar inositol y todas asimilaron el glicerol. En el grupo de las cepas Kazachstania asimilaron todos las fuentes de carbono ensayadas, excepción de inositol, ramnosa y salicin, estos resultado son similares a los de Liu et al., (2008) para K. exigua. Las especies del género Trichosporon presentan diferencias con respecto al perfil de asimilación de fuente de carbono, para las cepas de T. lignícola (PP2, PR11 y PR12), la cepa PR11 no asimiló D-Arabinose, D-Ribose, Eritritol y L-Rhamnose a diferencia de PR12 y PP2 que lo hicieron. Para el caso de T. dulcitum la cepa PR27 no asimiló D-Arabinose, D-
Ribose, L-Arabinose, L-Rhamnose y Melibiose en comparación con las otras cepas evaluadas (PR1, PR3, PR4, PR5, PR8, PR10, PR23, PR24, PR25, PR26). Al analizar otros perfiles de asimilación de fuente de carbono de algunas cepas de referencia de T. dulcitum [CBS 8257, CBS 5785, CBS 5786, CBS 7608, CBS 8258 (http://www.cbs.knaw.nl/) ] se puede apreciar que entre ellas existen diferencias en los perfiles de asimilación de fuente de carbono: D-Ribosa, L-Rhamnose, Rafinosa, Ribitol y Salicin situación que también se presenta en las cepas evaluadas en el presente estudio, en donde existen diferencias en la asimilación de azucares. Para T. porosum (PP4, B2, B3, B5, B6, B16, B21), la cepa PP4 presentó diferencias en la asimilación de las siguientes fuentes de carbono D-Arabinose, D-Ribose, L-Rhamnose, Eritritol y Almidón, siendo positiva o positiva débilmente para el resto de las cepas. Estos resultados son similares a los presentados por Middelhoven et al., (2001) para $T$. porosum CBS $2040,8396,8397$ y 8522 , en donde se difiere, con respecto al presente estudio, en la asimilación positiva para almidón (Tabla 2) 
Tabla 2. Asimilación de Fuentes de carbono por cepas de levaduras de suelo trumao.

\begin{tabular}{|c|c|c|c|c|c|c|c|c|c|c|}
\hline Especies & $\mathrm{Cn}^{*}$ & $\mathrm{Cs}^{*}$ & $\mathbf{D h}^{*}$ & $\mathrm{Ke}^{*}$ & $\mathrm{Pf}^{*}$ & $\mathrm{Ss}^{*}$ & $\mathbf{T d}^{*}$ & $\mathrm{Tl}^{*}$ & $\operatorname{Tm}^{*}$ & $\mathbf{T p}^{*}$ \\
\hline Número de cepas & 1 & 1 & 9 & 38 & 1 & 5 & 11 & 3 & 1 & 7 \\
\hline \multicolumn{11}{|l|}{ Fuentes de carbono } \\
\hline Cellobiose & + & + & + & + & - & + & W & + & + & + \\
\hline Citrate & + & + & + & + & + & + & + & + & + & + \\
\hline D-Arabinose & $\mathrm{w}$ & $\mathrm{w}$ & - & + & $\mathrm{W}$ & $\mathrm{w}$ & $(-/+)$ & $(-/+)$ & + & $(-/+)$ \\
\hline D-Glucitol & + & + & + & + & - & + & + & + & + & + \\
\hline D-Glucose & + & + & + & + & + & + & + & + & + & + \\
\hline DL-Lactate & $\mathrm{w}$ & $\mathrm{w}$ & + & + & + & - & + & + & $\mathrm{W}$ & - \\
\hline D-Ribose & - & - & $\mathrm{w}$ & + & - & - & $(-1+)$ & $(-1+)$ & - & $(-/+)$ \\
\hline D-Xylose & + & + & $\mathrm{w}$ & + & + & + & + & + & + & + \\
\hline Erythritol & - & - & + & + & - & - & + & $(-1+)$ & + & $(-/+)$ \\
\hline Glycerol & + & + & + & + & + & + & + & + & + & + \\
\hline Inositol & - & - & - & - & - & - & - & - & - & - \\
\hline L-Arabinose & + & $\mathrm{w}$ & $\mathrm{w}$ & + & $\mathrm{W}$ & + & $(-/+)$ & + & + & + \\
\hline L-Rhamnose & - & - & $\mathrm{w}$ & - & - & - & $(-/+)$ & $(-/+)$ & - & $(-/+)$ \\
\hline L-Sorbose & + & + & $\mathrm{w}$ & + & - & + & $\mathrm{w}$ & + & + & + \\
\hline Melezitose & + & + & + & + & - & + & + & + & + & + \\
\hline Melibiose & + & + & - & + & - & + & $(-/+)$ & + & W & + \\
\hline Raffinose & + & + & $\mathrm{w}$ & + & - & + & + & + & + & + \\
\hline Ribitol & + & + & + & + & W & + & + & + & + & + \\
\hline Salicin & + & + & + & - & W & + & + & + & + & $\mathrm{w}$ \\
\hline Starch & + & w & + & + & W & w & + & $\mathrm{w}$ & + & $(-/+)$ \\
\hline Succinate & + & + & + & + & + & + & + & $\mathrm{w}$ & + & $\mathrm{w}$ \\
\hline \multicolumn{11}{|c|}{$\begin{array}{l}\text { *Abreviación delnombre dela levaduras: Candida sp. (Cn), cepa PR28. Candida saitoana(Cs), cepa PR16. } \\
\text { Devariomyces hansenii (Dh), cepas PP1, B1, B4, B7, B9, B18, B20, B26, B28. Kazachstania exigua (Ke), } \\
\text { cepas PP5, PP6, PP7, PP8, PP9, PP10, PP11, PP12, PP13, PP14, PP15, PP16, PP17, PP18, PP19, PP20, } \\
\text { PP21, PP22, PP23, PP24, PP25, PP26, PP27, PP28, PP29, PP30, PR5, PR13, PR14, PR15, PR17, PR18, } \\
\text { PR19, PR20, PR21, PR22, PR30, B29. Pichia fermentans (Pf), cepa B27. Schizoblastoporiom } \\
\text { starkeyiihenricii (Ss), cepas PR2, PR7, PR9, B10, B11. Trichosporon ducitum (Td), cepas PR1, PR3, PR4, } \\
\text { PR5, PR8, PR10, PR23, PR24, PR25, PR26, PR27. Trichosporon lignicola (T1), cepas PP2, PR11, PR12; } \\
\text { Trichosporon miniiliforme (Tm), cepa PR29. Trichosporon porosum (Tp) cepas PP4, B2, B3, B5, B6, B16, } \\
\text { B21. - = negativa, += positive, w = positive débil. (-/+). = positive o negativa para algunas cepas. }\end{array}$} \\
\hline
\end{tabular}




\begin{tabular}{|c|c|c|c|c|c|c|c|c|c|c|}
\hline Especies & $\mathrm{Cn}^{*}$ & $\mathrm{Cs}^{*}$ & $\mathrm{Dh}^{*}$ & $\mathrm{Ke}^{*}$ & $\mathrm{Pf}^{*}$ & $\mathrm{Ss}^{*}$ & $\mathbf{T d}^{*}$ & $\mathrm{Tl}^{*}$ & Tm* & $\mathbf{T} \mathbf{p}^{*}$ \\
\hline Numero de cepas & 1 & 1 & 9 & 38 & 1 & 5 & 11 & 3 & 1 & 7 \\
\hline \multicolumn{11}{|l|}{ Fuente de carbono } \\
\hline \multicolumn{11}{|l|}{ Fermentacion } \\
\hline D-Galactose & - & - & - & - & - & - & - & - & - & - \\
\hline D-Glucose & + & + & - & + & + & - & - & - & - & - \\
\hline D-Xylose & - & - & - & - & - & - & - & - & - & - \\
\hline Fructose & + & - & - & + & W & - & - & - & - & - \\
\hline Lactose & - & - & - & - & - & - & - & - & - & - \\
\hline Maltose & - & - & - & - & - & - & - & - & - & - \\
\hline Starch & + & + & + & + & W & - & - & - & - & - \\
\hline Sucrose & - & - & - & - & - & - & - & - & - & - \\
\hline$\alpha, \alpha$-Trehalose & - & - & - & - & - & - & - & - & - & - \\
\hline
\end{tabular}

Asimilación de

Nitrogeno

\begin{tabular}{lcccccccccc}
\hline Nitrato & - & + & - & - & - & - & + & - & + & - \\
Nitrito & $\mathrm{w}$ & - & + & $\mathrm{w}$ & $\mathrm{w}$ & $\mathrm{w}$ & + & $\mathrm{w}$ & - & + \\
Urea (hidrolisis) & $\mathrm{w}$ & $\mathrm{w}$ & + & $\mathrm{w}$ & - & + & $\mathrm{w}$ & + & - & + \\
\hline
\end{tabular}

*Abreviación del nombre dela levaduras: Candida sp. (Cn), cepa PR28. Candida saitoana(Cs), cepa PR16. Devariomyces hansenii (Dh), cepas PP1, B1, B4, B7, B9, B18, B20, B26, B28. Kazachstania exigua (Ke), cepas PP5, PP6, PP7, PP8, PP9, PP10, PP11, PP12, PP13, PP14, PP15, PP16, PP17, PP18, PP19, PP20, PP21, PP22, PP23, PP24, PP25, PP26, PP27, PP28, PP29, PP30, PR5, PR13, PR14, PR15, PR17, PR18, PR19, PR20, PR21, PR22, PR30, B29. Pichia fermentans (Pf), cepa B27. Schizoblastoporiom starkeyiihenricii (Ss), cepas PR2, PR7, PR9, B10, B11. Trichosporon ducitum (Td), cepas PR1, PR3, PR4, PR5, PR8, PR10, PR23, PR24, PR25, PR26, PR27. Trichosporon lignicola (T1), cepas PP2, PR11, PR12; Trichosporon miniiliforme (Tm), cepa PR29. Trichosporon porosum (Tp) cepas PP4, B2, B3, B5, B6, B16, B21. - = negativa, $+=$ positive, $\mathrm{w}=$ positive débil. $(-/+) .=$ positive o negativa para algunas cepas .

Tabla 3. Fuentes de carbono fermentadas y fuentes de nitrógeno asimiladas por cepas de levaduras de suelo tumao.

Por su parte para la fermentación de fuentes de carbono (Tabla 3), los resultados indican que todas las cepas fermentaron glucosa con excepción de D. hansenni; S. starkeyiihenricii y las del género Trichosporon (T. ducitum; T. lignícola; T. moniliforme y $T$. porosum). La fermentación de otras fuentes de carbono para las especies del género Trichosporon fue negativa al igual que las cepas de referencia analizadas (CBS 8257, CBS 5785, CBS 5786, CBS 7608, CBS 8258). Las cepas de levaduras del género Devariomyces no fermentaron glucosa y los perfiles de asimilación de carbono son similares a lo propuesto por Kurtmaz et al., (2011).

En cuanto al perfil de asimilación de fuentes de nitrógeno (Tabla 3), todas las cepas de re- 
ferencia asimilaron nitrato, hidrolizaron la urea y fueron negativas para nitrito, a diferencia de las cepas estudiadas en el presente trabajo que difiere por la asimilación positiva de nitrito de algunas cepas. Con respecto al género Candida Yan et al., (2014), señalan que Candida mycoderma obtenidas desde un suelo de arroz de la provincia de Jiangxi de China presentaron una asimilación de compuestos de nitrógeno positivas para KNO3 y urea. Barnet et al, 1990, señala que el género Candida puede presentar cepas nitrato positiva o negativas (+/-) e hidrolisis de la urea negativa (-). Las cepas PR16 y PR28 aisladas en el presente trabajo fueron débilmente positivas para la urea y la cepa PR 16 asimilo positivamente el nitrato a diferencia de PR28 que fue negativa. Además las cepas PR16 y PR28 el perfil de asimilación de fuente de carbono es similar entre ellas, la asimilación de compuestos nitrogenados varía en la asimilación de nitrato y la fermentación es positiva para glucosa, en ambos casos.

\section{CONCLUSIONES}

Este estudio ha provisto una primera información acerca de las levaduras asociadas a suelo con distintos manejos agrícolas en la región de los Ríos, Chile. La metodología utilizada PCRRFLP se presentó como una buena técnica (rápida y fiable) para la identificación de levaduras, con la desventaja de que al no encontrar un patrón de bandas igual no se logra realizar la identificación. Sin embargo al complementarlo con la secuenciación del DNA de las levaduras se ha logrado la identificación de las cepas y también la confirmación de la identificación utilizando la metodología PCR-RFLP. Además se ha podido caracterizar fisiológicamente levaduras autóctonas del sur de Chile, con potenciales biotecnológicos (levaduras para biofertilizantes y levaduras oleaginosas) que pueden ser evaluados a futuro en otras investigaciones.

\section{AGRADECIMIENTOS}

Los autores agradecen al proyecto FONDECYT 1141066 y a la Beca Doctorado Nacional CONICYT; Folio: 21140135.

\section{REFERENCIAS}

Barnett J., Payne R. y Yarrow D. (1990). Yeasts: Characteristics and Identification. 2nd edn. Cambridge. Cambridge University Press. p. 38.

Barnett A ., Payne, W. y Yarrow D. (2000). Yeast: Characteristics and Identification, 3rd ed., Cambridge University Press, Cambridge.

Botha A. (2011). The importance and ecology of yeasts in soil. Soil Biology y Biochemistry, 43:1-8.

Chang Y., Chang K., Hsu C., Chuang L., Chen C., Huang F. y Jang H. (2013). A comparative study on batch and fed-batch cultures of oleaginous yeast Rhodosporidium toruloides. Nat. Commun. 2012:11-12
Esteve-Zarzoso B., Belloch C., Uruburu, F. y Querol, A. (1999). Identification of yeasts by RFLP analysis of the5.8S rRNA gene and the two ribosomal internal transcribed spacers. Int. J. Syst. Bacteriol. 49: 329-337.

Fernández-González M., Espinosa, J., Úbeda J. y Briones, A. (2001). Yeast present during wine fermentation: Comparative analysis of conventional plating and PCR-TTGE .Syst. Appl. Microbiol. 24: 634-638.

Fonseca A. y Inacio J. (2006). Phylloplane yeasts. In: Rosa C, Peter G (eds) Biodiversity and ecophysiology of yeasts. Springer, Berlin, 263-301 pp. 
Kitcha S y Cheirsilp B. (2011). Screening of Oleaginous Yeasts and Optimization for Lipid Production Using Crude Glycerol as a Carbon Source. Energy Procedia 9: $274-282$.

Kreger-van Rij N. (1994). The yeast. A taxonomic study, Third revised and enlarged edition. The Netherlands. 79 p.

Kupper K., Bettiol W., de Goes A., de Souzac P, y Bellotte J. (2006). Biofertilizer for control of Guignardia citricarpa, the causal agent of citrus black spot. Crop Protection 25 569-573.

Kurztman C., Fell J. y Boekhout T. (2011). Yeast a Taxonomic Study. The Fifth Edition. Amsterdam. Elsevier. 364 p.

Li Y., Zhao Z. y Bai F. (2007). High-density cultivation of oleaginous yeast Rhodosporidium toruloides Y4 in fed-batch culture. Enzyme Microb. Technol. 41:312-317

Liu Y., Chun-Hao L., Shuh-Sen Y. y Ching-Fu Lee. (2008). New Records of Kazachstania Species in Taiwan. Taiwania, 53(3): 293-300.

Lozano C., Barahona S., Reyes E., Lodato P., Retamales P., León R., Urzúa B. y Cifuentes V. (2002). Estudio genético molecular de levaduras de diversos ambientes. Boletín Micológico, 17: $109-114$.

Mestre M., Rosa C., Safar S., Libkind D. y Fontenla S. (2011). Yeast communities associated with the bulk-soil, rhizosphere and ectomycorrhizosphere of a Nothofagus pumilio forest in northwestern Patagonia, Argentina. Microbiology Ecology, 78: 531-541.

Middelhoven W., Scorzetti G. y Fell J. (2001). Trichosporon porosum comb. nov., an anamorphic basidiomycetous yeast inhabiting soil, related theloubieri/laibachii group of species that assimilate hemicelluloses and phenolic compounds. FEMS Yeast Research, 1:15-22

Nguyen H., Gaillardin C. y Neuvéglise, C. (2009). Differentiation of Debaryomyces hansenii and Candida famata by rRNA gene intergenic spacer fingerprinting and reassessment of phylogenetic relationships among $D$. hansenii, C. famata, D. fabryi, C. flareri (=D. subglobosus) and D. prosopidis: description of $D$. vietnamensis sp. nov. closely related to D. nepalensis. FEMS Yeast Research, 9: 641-662.

Papanikolaou S. y Aggelis G. (2002). Lipid productionby Yarrowia lipolytica growing on industrial glycerol in a single-stage continuous culture. Bioresour. Technol. 82: 43-49

Pham T., Wimalasena T., Box W., Koivuranta K., Storgårds E., Smart K. y Gibson B. (2011). Evaluation of ITS PCR and RFLP for differentiation and identification of brewing yeast and brewery 'wild' yeast contaminants. J. Inst. Brew. 117(4), 556-568.

Romero P., Patiño B., Quirós M., González-Jaén M., Valderrama M., de Silóniz M. y Peinado, J. (2005). Differential detection of Debaryomyces hansenii isolated from intermediate-moisture foods by PCR-RFLP of the IGS region of rDNA. FEMS Yeast Research 5:455-461.

Segura L., Kirchmayr M., Flores E. y Gschaedler A. (2010).PCR-RFLP of the ITS-5.8S regions as an identification tool for yeasts: advantages and disadvantages. e-Gnosis, 8: 1-12.

Slavikova E. y Vadkertiova R. (2000). The occurrence of yeasts in the forest soils. J. Basic Microbiol, 40: 207-212.

Slavikova E. y Vadkertiova R. (2003). The diversity of yeasts in the agricultural soil. J. Basic Microbiol, 43:430-436. 
Sugita T., Masamitsu N., Reiko I., Toshiharu M. y Takako S. (2002). Sequence Analysis of the Ribosomal DNA Intergenic Spacer 1 Regions of Trichosporon Species. Journal of Clinical Microbiology. 40: 1826-1830.

Wuczkowski M. y Prillinger H. (2004). Molecular identification of yeasts from soils of the alluvial forest national park along the river Danube downstream of Vienna, Austria ("National park donauauen"). Microbiological Research, 159: 263-275.
Yan, M., Yu L., Zhang L., Guo Y., Dai K. y Chen, K. (2014). Phosphatase activity and culture conditions of the yeast Candida mycoderma sp. And analysis of organic phosphorus hydrolysis ability. Journal of Environmental Sciences, 26: 2315-2321

Yurkov A., Kemler M. y Begerow D. (2012). Assessment of yeast diversity in soils under different management regimes. Fungal Ecology, 5: 24-35 